\title{
PATTERN OF SURGICAL TRAUMA- A RETROSPECTIVE STUDY
}

\author{
Raj Kumar Singh1, Rajesh Kumar Maurya², Krishna Bahadur Mishra ${ }^{3}$, Saurabh Singh ${ }^{4}$
}

${ }^{1}$ Associate Professor, Department of Surgery, GSVM Medical College, Kanpur, Uttar Pradesh.

${ }^{2}$ Associate Professor, Department of Surgery, GSVM Medical College, Kanpur, Uttar Pradesh.

${ }^{3}$ Professor, Department of Surgery, GSVM Medical College, Kanpur, Uttar Pradesh.

4Junior Resident, Department of Surgery, GSVM Medical College, Kanpur, Uttar Pradesh.

\begin{abstract}
\section{BACKGROUND}

Surgical trauma is known to be an important public health problem throughout the world and so also in metropolitan cities in our country, due to erratic traffic and poor response by onlookers as well as poorly organised pre-hospital care and transportation to tertiary care centre. So, we have studied our hospital data for our introspection for improving overall management of surgical trauma victims.
\end{abstract}

\section{MATERIALS AND METHODS}

A total number of 2094 cases of surgical trauma patients admitted in Department of Trauma and Emergency Surgery at LLR Hospital, GSVM Medical College, Kanpur, UP, India from January 2015 to December 2015 were studied. The road traffic accidents and fall from height were included in our study. We analysed our data in relation to age and sex distribution, injury pattern, complexity of injuries with mortality.

\section{RESULTS}

$45 \%$ cases were in age group of 31 to 50 years with $20 \%$ between 51 to 70 years of age group. Males were predominant i.e. $64 \%$ were male and $36 \%$ were female. $85 \%$ cases were from road traffic accidents and $15 \%$ were height from fall. $4.5 \%$ were chest injuries and 5.2\% were abdominal injuries. The head injuries were predominant (78.22\%). Among the head injuries, cases of SDH were $15.75 \%$, EDH were $12.82 \%$, SAH were $12.57 \%$, rest were cerebral concussion and scalp injuries. The overall mortality was $16.72 \%$ and maximum were from road traffic accidents $(85 \%)$.

\section{CONCLUSION}

The complexity of surgical/traumatic injuries leads to major challenges which include involvement of multispecialty and dedicated trauma team along with diagnostic facilities and emphasis on pre-hospital care by trained paramedical staff in surgical trauma care, and earliest transportation to nearest hospital and further to tertiary care centres.

\section{KEYWORDS}

Surgical Trauma, Injuries, Patterns, Road Traffic, Fall from Height.

HOW TO CITE THIS ARTICLE: Singh RK, Maurya RK, Mishra KB, et al. Pattern of surgical trauma- A retrospective study. J. Evolution Med. Dent. Sci. 2017;6(52): 3988-3991, DOI: 10.14260/Jemds/2017/862

\section{BACKGROUND}

Surgical traumas are extremely important public health problems in both developed and developing countries. Various traumas contribute to some $1 / 3^{\text {rd }}$ of death of entire human population followed by cardiovascular disease \& Cancer. ${ }^{1}$ Surgical trauma related mortality and morbidity rates are on the rise, leads to financial losses not only because of work place absence or treatment cost but also because they might cause various disabilities. Special diagnosis and therapeutic difficulties occur in case of severe, multiple and multiorgan injuries as these injuries cause numerous pathophysiological and metabolic effect on body.

Financial or Other, Competing Interest: None.

Submission 23-05-2017, Peer Review 16-06-2017,

Acceptance 22-06-2017, Published 29-06-2017.

Corresponding Author:

Krishna Bahadur Mishra,

A-11, Deewah Kumy,

AWHO Complex,

D-Block, Shyam Nagar,

Kanpur, Uttar Pradesh.

E-mail:kbm.mishra@gmail.com

DOI: $10.14260 /$ jemds $/ 2017 / 862$

(c) $($ ) $\$$
So, we have analysed our hospital data to understand the epidemiology of trauma which might improve hospital's ability to provide a comprehensive management to surgical trauma victims.

\section{MATERIALS AND METHODS}

The authors of this study performed a retrospective analysis on 2094 cases admitted in Department of Trauma and Emergency Surgery of LLR Hospital, Kanpur. The injuries which occurred between January 1, 2015 and December 31, 2015 were included in study. We have recorded the injury pattern, GCS Scale level and presence/absence of Peripheral Circulatory failure on admission.

We have included only two modes of injuries, road traffic accidents and fall from height.

\section{RESULTS}

We have studied a total of 2094 cases in a period of one year (Jan. 2015 - Dec. 2015). 


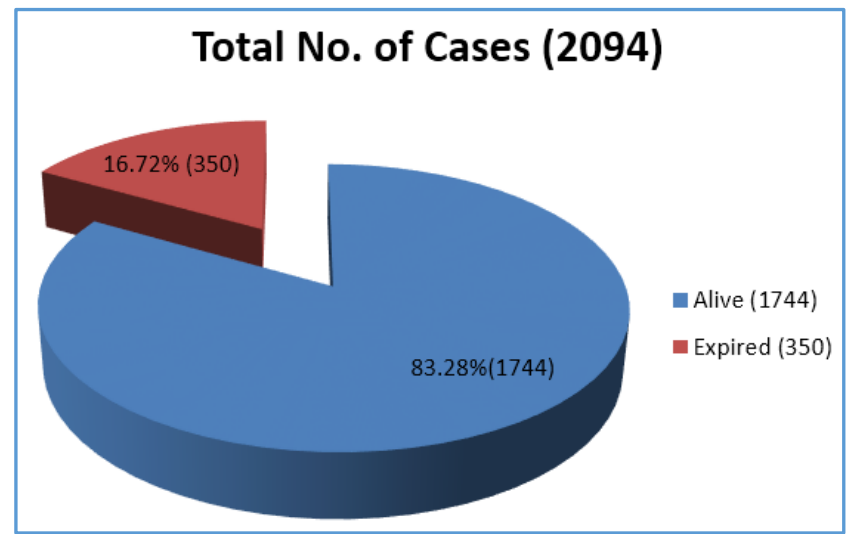

Figure 1

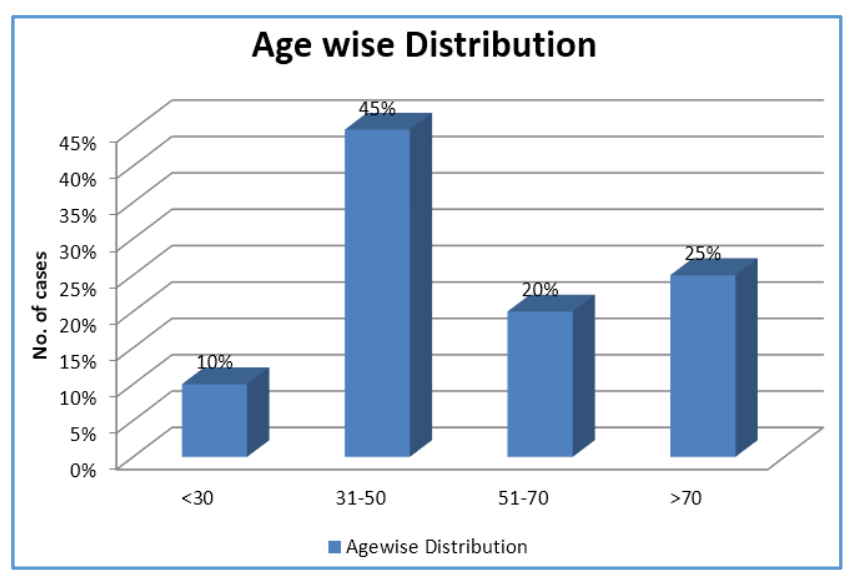

Figure 2

Majority of patients are from 31 - 50 age group and $2^{\text {nd }}$ most common are from $>70$ years of age.

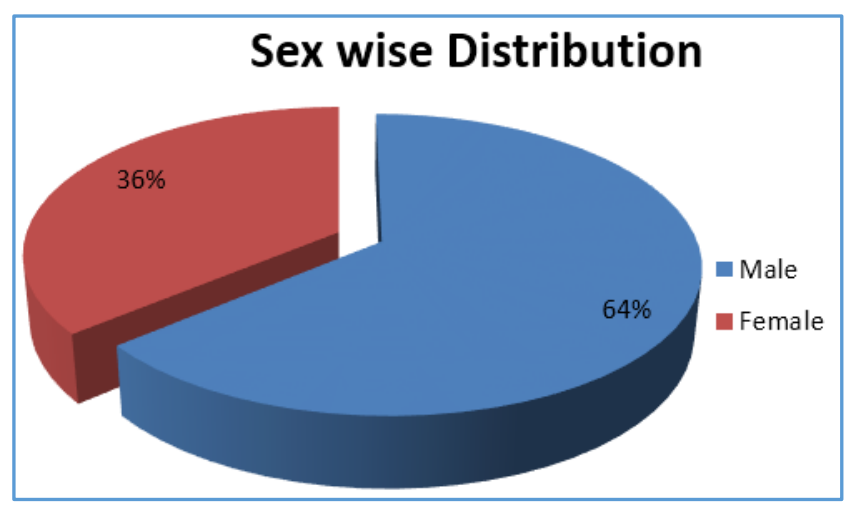

Figure 3

In our study, $2 / 3^{\text {rd }}$ of the patients were male and $1 / 3^{\text {rd }}$ were female.

\begin{tabular}{|c|c|c|}
\hline Mode of Injury & No. of Patients & $\mathbf{\%}$ \\
\hline Road Traffic Accidents & 1778 & 85 \\
\hline Fall from Height & 316 & 15 \\
\hline \multicolumn{2}{|c|}{ Figure 4 } \\
\hline
\end{tabular}

We studied only two modes of injuries.

1. RTA.

2. Fall from height.

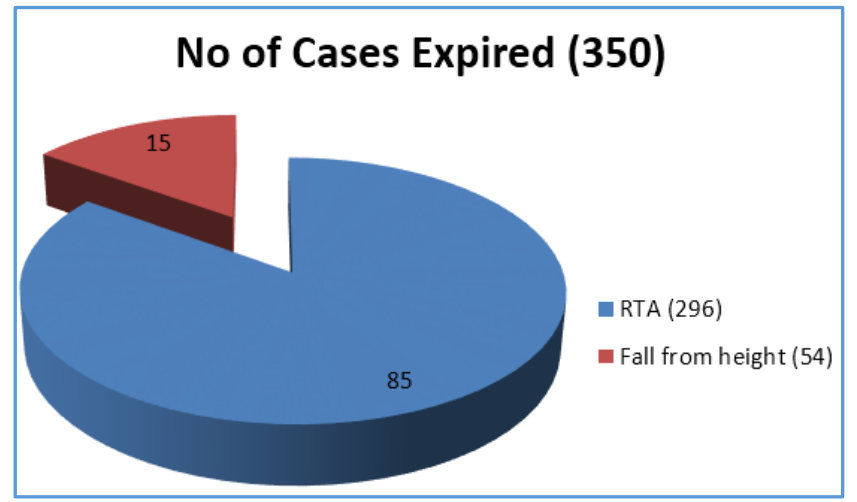

Figure 5

Total no. of cases expired in our study are 350, 296 because of RTA and 54 because of fall from height.

\begin{tabular}{|c|c|c|}
\hline RTA. & Percentage & No. of Cases \\
\hline With Shock & $10 \%$ & 178 \\
\hline Without Shock & $90 \%$ & 1600 \\
\hline \multicolumn{3}{|c|}{ Figure 6 } \\
\hline
\end{tabular}

\begin{tabular}{|c|c|c|}
\hline RTA Without Shock & Percentage & No. of Cases \\
\hline Head Injury with other injury & $14 \%$ & 224 \\
\hline Only head Injury & $86 \%$ & 1376 \\
\hline \multicolumn{3}{|c|}{ Figure 7 } \\
\hline
\end{tabular}

\begin{tabular}{|c|c|c|}
\hline RTA with Shock & Percentage & No. of cases \\
\hline Head Injury with other injury & 100 & 178 \\
\hline Only head Injury & - & - \\
\hline \multicolumn{2}{|c|}{ Figure 8 } \\
\hline
\end{tabular}
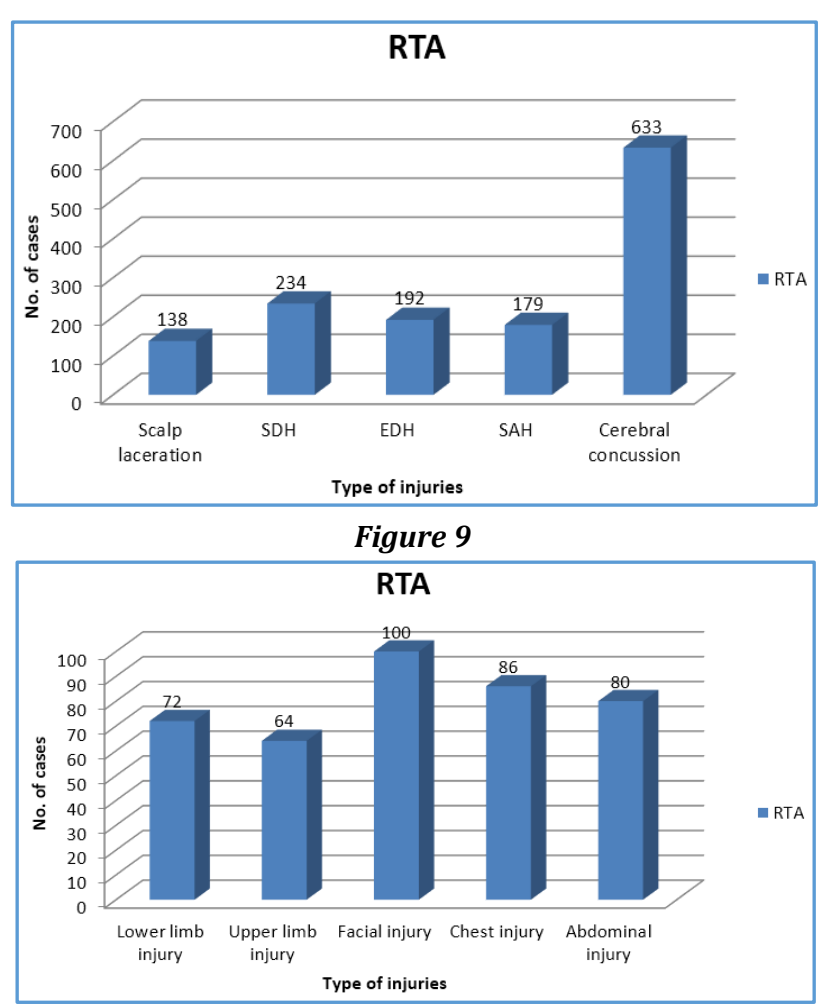

Figure 10

\begin{tabular}{|c|c|c|}
\hline Patients Expired Due to RTA (n=296) & No. of Cases & $\mathbf{\%}$ \\
\hline Head Injury & 192 & 64 \\
\hline Abdominal Injury & 74 & 25 \\
\hline Chest injury & 30 & 11 \\
\hline \multicolumn{2}{|c|}{ Figure 11 } \\
\hline \multicolumn{2}{|c}{}
\end{tabular}




\begin{tabular}{|c|c|c|}
\hline Fall from Height (n= 316) & Percentage & No. of Cases \\
\hline With Shock & 10 & 32 \\
\hline Without Shock & 90 & 284 \\
\hline \multicolumn{2}{|c|}{ Figure 12 } \\
\hline
\end{tabular}

\begin{tabular}{|c|c|c|}
\hline $\begin{array}{c}\text { Fall from Height } \\
\text { without Shock (n= 284) }\end{array}$ & Percentage & $\begin{array}{c}\text { No. of } \\
\text { Cases }\end{array}$ \\
\hline Head Injury with other injury & 20 & 56 \\
\hline Head Injury without other injury & 80 & 228 \\
\hline \multicolumn{2}{|c|}{ Figure 13 } \\
\hline
\end{tabular}

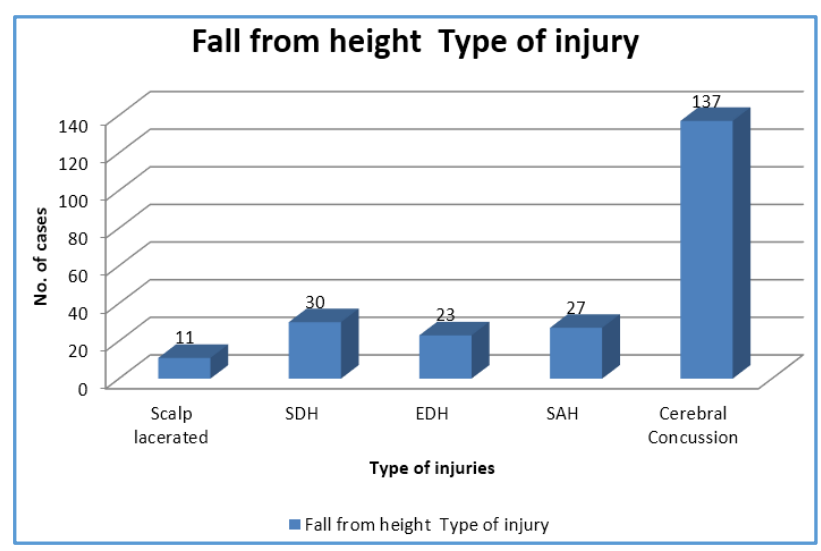

Figure 14

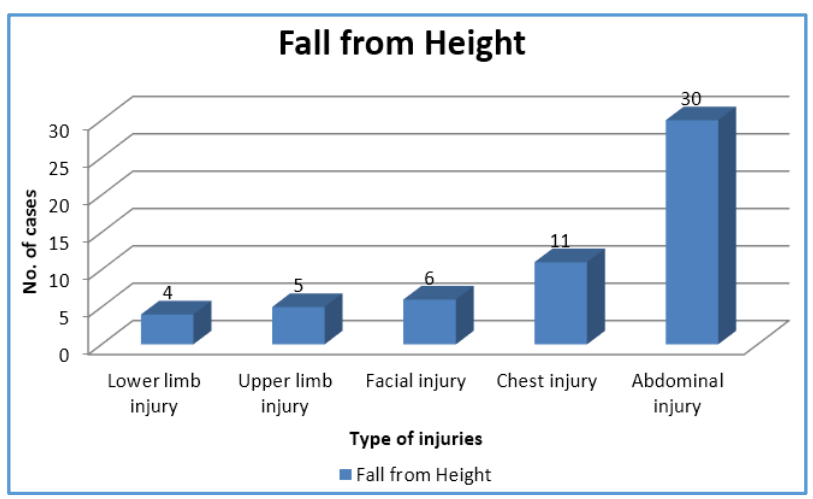

Figure 15

\begin{tabular}{|c|c|c|}
\hline $\begin{array}{c}\text { Patients Expired Due to Fall } \\
\text { from Height (n=54) }\end{array}$ & No. of Cases & \% \\
\hline Head Injury & 19 & 35 \\
\hline Abdominal Injury & 26 & 48 \\
\hline Chest injury & 9 & 17 \\
\hline \multicolumn{2}{|c|}{ Figure 16 } \\
\hline
\end{tabular}

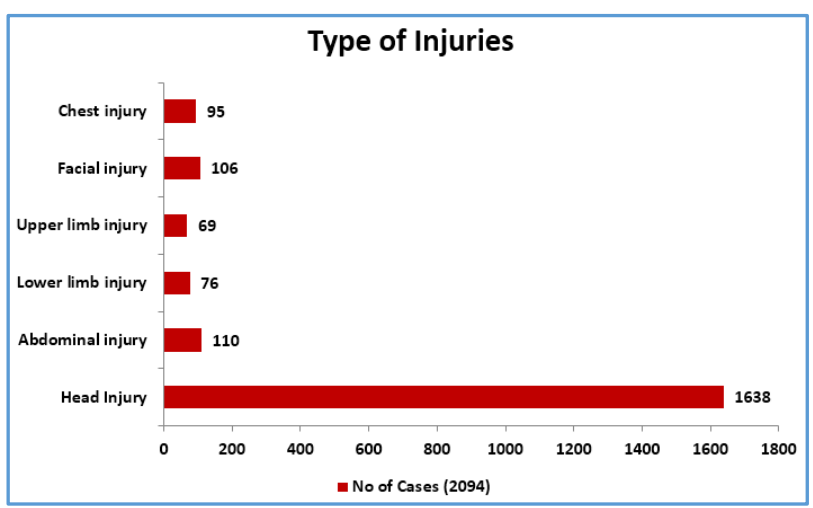

Figure 17
Patients presented with various type of injuries, majority are of head injuries.

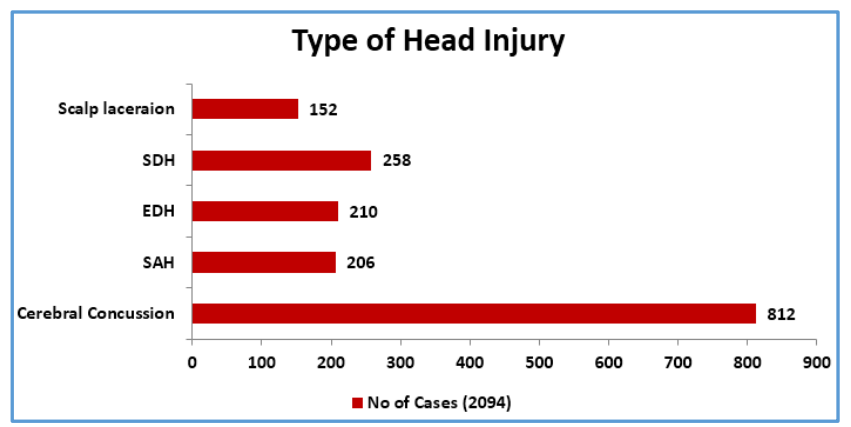

Figure 18, SDH, EDH, SAH.

In head injuries, most common type is cerebral concussion and other types are SDH, EDH, SAH.

\section{RESULTS}

Total number of 2094 cases were analysed among which $16.72 \%$ (350) cases expired, 83.28\% (1744) were alive. Patients having history of RTA were 1778 (85\%) and with fall from height were 316 (15\%).

Among RTAs, no. of cases with shock were 178 (10\%) and without shock were 1600 (90\%). Patients having head injury with other injuries were 402 and having head injury only were 1376. RTA patients with head injury having scalp laceration were 138, with SDH were 234, with EDH were 192 with SAH were 179, with cerebral concussion were 633 (various degrees of diffuse axonal injuries and multiple cerebral contusions were associated in some cases) and RTA patients with other injuries like lower limb injury were 72 , upper limb injury were 64 , facial injury were 100 , chest injury were 86 and abdominal injuries were 80 .

Total number of patients expired due to road traffic accidents-296, among which 82 patients expired because of EDH, 74 expired because of SDH, 36 expired because of SAH, 30 died due to chest injuries and 74 died due to abdominal injuries (Blunt trauma abdomen).

Patients having history of fall from height were 316, among which total number of cases with shock were 32 (10\%) and number of cases without shock were 284 (90\%).

Among patients having fall from height history, number of cases with scalp lacerations were 11 and number of cases with SDH were 24, number of cases with EDH were 23, number of cases with SAH were 27 and number of cerebral concussion cases were 137.

Patients also having other injuries such as lower limb injury 4 cases, upper limb injury 5 cases, facial injury 6 cases, chest injury 11 cases and abdominal injury 30 cases.

Number of patients expired due to fall from height-34, among which 10 cases were because of EDH, 4 cases of SDH, 3 cases of SAH. 9 cases due to chest injuries and 26 cases due to abdominal injuries.

\section{DISCUSSION}

Our study shows that injuries due to Road Traffic Accidents $(85 \%)$ were higher than fall from height. Majority of cases are seen in 31 - 50 years age group.

Initial treatment to patients who sustained injuries was provided by primary physicians, general surgeons in peripheral hospitals/clinics, and patients were transferred to 
our hospital. These patients were managed with multispecialty discipline as per requirements.

Road traffic accidents are among the leading causes of trauma and death in worldwide in individuals younger than 45 years and as we studied in Kanpur (India) it is also a major cause of trauma and trauma care system and quality of care are not well described in Kanpur. There is sustained increase in injuries in India which may be explained by the 473 -fold increase in Registered Motor Vehicle observed within last 60 years. Kanpur is one of the fastest growing city in India with poor road traffic discipline. The travel pattern in Kanpur is characterised by the presence of heterogenous type of vehicles of different size, shapes and engine capacity. The non-motorised transport varies from 30 to $70 \%$ during peak hours in Kanpur depending on time and the location. Bicycle \& two-wheeler transport without helmet remains a major mode of travel in rural areas as well as in city of Kanpur. $23.2 \%$ of all fatal accidents are by two wheelers.(2) Communication system in case of RTA in India represents a bottleneck of care. Only $14 \%$ of systems have a dedicated central telephonic number for incident reporting. There is lack of pre-hospital care in most rural and semi-urban areas in Kanpur and almost 70\% of severely injured persons reach LLR Hospital without any pre-hospital care or a very minimal care. Further cause of delay in treatment is due to poor transport services with no assistance of paramedics during transportation.

In Germany, the highest number of deaths 21300 occurred in 1973. The improvement in mortality in Germany was from implementation of pre-hospital measure and advanced trauma life support measure with established guideline and qualified specialists experienced in caring for high volume of severely injured patients. These measures will also be effective in India but effective management of injured patients are still in early stage. $(3,4,5)$

According to census 2011, 5\% and 21\% of Indian Households own a four wheeler and a two wheeler respectively.(6) Survey by National Council of Applied Economic Research (NCAER) has shown that 5\% Households owned a car and 15\% households owned a motor cycle in 2005 - 2006.(7)

The difference in our studies and other studies has shown a major lag in Pre-hospital care, non-availability of trained paramedics during transportation of severely injured patients with apathetic attitude of public in general.

Pedestrians are more vulnerable to injury and death. This may be due to number of factors, including lack of pedestrian facilities in road design, poor knowledge and practice of road safety of measure by General population, uncourteous behaviour of motorists, high speed driving and low level of vehicle ownership. $(8,9,10)$

In 2006, American authors published an article in which they looked at mortality rate in 52 hospitals out of which one was as a trauma centre and 51 were non-trauma hospitals located in States. Researchers found that mortality rate was higher in a Non-trauma Hospital than in a trauma centre respectively i.e. $9.5 \%$ and $7.6 \% .(11)$ In our study, mortality rate was $16.72 \%$ in which RTA accounts to $85 \%$ and fall from height to $15 \%$; death is mainly due to severity of accidents.
A Canadian study (a study from 2000 - 2003) revealed that elderly constituted $30 \%$ of patients admitted to trauma centre which is almost similar to our study.(12)

\section{CONCLUSION}

This retrospective study shows high incidence of head injury in RTA in reproductive age group which is leading to high cost of management, mortality and morbidity with lifelong disability. This is a major concern in government hospitals, government should provide extra facilities in peripheral hospitals, provisioning initial care to severely injured patients.

\section{REFERENCES}

[1] Jojczuk M, Nogalski A, Kucmin T, et al. Distribution of injury among patients of department of trauma and emergency medicine of independent public teaching hospital no 1 in 2011. POI J Public Health 2016;126(1):37-40.

[2] Deshmukh VU, Ketkar MN, Bharucha EK. Analysis of trauma outcome using the TRISS method at a tertiary care centre in Pune. Indian J Surg 2012;74(6):440-4.

[3] Hulka F, Mullins RJ, Mann NC, et al. Influence of a statewide trauma system on pediatric hospitalization and outcome. J Trauma 1997;42(3):514-9.

[4] Shackford SR, Mackersie RC, Hoyt DB, et al. Impact of a trauma system on outcome of severely injured patients. Arch Surg 1987;122(5):523-7.

[5] Rutledge R, Fakhry SM, Meyer A, et al. An analysis of the association of trauma centers with per capita hospitalizations and death rates from injury. Ann Surg 1993;218(4):512-21.

[6] Chandramouli C. Houses, Household Amenities and Assets Data 2001-2011-Visualizing Through Maps [Internet]: Office of Registrar General of India, 2012. Available from: http://censusindia.gov.in/2011Common/NSD/Houses_household.pdf.

[7] Shukla RK, Dwivedi SK, Sharma A. The great Indian research's market information survey of household. [Internet]: National Council of Applied Research 2005. Available from: http://www. Ncaer.org/ downloads/PPT/thegreatindianmarket.

Pdfwww.ncaer.org

[8] Crandall JR, Bhalla KS, Madeley NJ. Designing road vehicles for pedestrian protection. BMJ 2002;324(7346):1145-8.

[9] Demetriades D, Murray J, Martin M, et al. Pedestrians injured by automobiles: relationship of age to injury type and severity. J Am Coll Surg 2004;199(3):382-7.

[10] Orsborn R, Haley K, Hammond S, et al. Pediatric pedestrian versus motor vehicle patterns of injury: debunking the myth. Air Med J 1999;18(3):107-10.

[11] MacKenzie EJ, Rivara EP, Jurkovich GJ, et al. A national evaluation of the effect of trauma-center care on mortality. N Engl J Med 2006;354(4):366-78.

[12] Gowing R, Jain MK. Injury patterns and outcomes associated with elderly trauma victims in Kingston, Ontario. Can J Surg 2007;50(6):437-44. 